\title{
Preparing Undergraduate Learners with Skills Required by a Transformative Work Environment
}

\author{
Upaasna Ramraj $^{1} \&$ Ferina Marimuthu ${ }^{1}$ \\ ${ }^{1}$ Durban University of Technology, South Africa \\ Correspondence: Upaasna Ramraj and Ferina Marimuthu, Durban University of Technology, Faculty of Accounting \\ and Informatics, PO Box 1334, Durban, South Africa
}

Received: July 7, 2020

Accepted: November 2, 2020

Online Published: November 10, 2020

doi:10.5430/ijhe.v10n1p287

URL: https://doi.org/10.5430/ijhe.v10n1p287

\begin{abstract}
Higher Education systems need to undergo significant transformation to produce graduates who are highly skilled and prepared for their roles in the impending workforce. Despite an improvement in university throughput rates, unemployment remains predominantly high, which could be attributed to the misalignment between mandatory workplace skills and those possessed by graduates. The focus of the study was on the exploration of skills acquired from the new General Education modules introduced into the curriculum of undergraduate programmes. Hence, the study discovered learners' perspectives on the relevance of the skills acquired from these modules in the undergraduate programme to ensure survival in the workforce. The methodology adopted in the study was a quantitative survey research design, using the questionnaire as the data collection tool from a census of the first-year learners registered in the undergraduate programme. The results provided significant evidence to support the view that the skills acquired from the General Education modules in the undergraduate programme are indispensable in industry and enhanced critical thinking of the learners.
\end{abstract}

Keywords: skills, innovation, curriculum, general education, business fundamentals

\section{Introduction}

Higher Education in the 21st century is a critical role-player in modern societies. Globally, there have been calls by institutions to prepare learners and help them navigate the world (Teo, 2019). Institutions are functioning in a complicated era, that is the Fourth Industrial Revolution (4IR), characterised by novel modifications. These organisations need to prepare for the 4IR to remain relevant in the world economy and along these lines must equip their employees for the forthcoming movements in the way they work (Lieu et al., 2018). The accelerated pace of functioning in 4IR may lead to an inadvertent disregard for the human element, which may be detrimental to organisations as it affects interpersonal communication skills and the ability to engage in business undertakings. For this reason and others, the Fifth Industrial Revolution (5IR) will be devoted to humanity and to preparing individuals for imminent difficulties (Ilieva-Nawful, 2020). According to Scepanović (2019), one of the challenges faced by universities is how to afford skills and knowledge to learners that will sustain them for long-term jobs. At the same time, industry expects graduates to have an education that aligns to labour market needs. The advent of the industrial revolutions does not in any way mean that people will become obsolete, instead consideration should be given strengthening their skills sets for seamless integration into the workforce. Essentially, the concept of Industry 4.0 describes the interconnection of individuals, objects and systems through real-time data exchange (Memi, 2020). Besides, employability is proving rather tricky as employers are expecting remarkable skills acquisition and wellrounded individuals who can adapt, be critical and think logically. Hill (2016) maintains that if skills are enforced, there will be an inevitable move towards participatory and self-regulatory teaching, learning and assessment. These attributes must be communicated across all levels in meaningful ways that are relevant to all students and taught within the formal curriculum (Jones \& Pate, 2019). It has emerged that Higher Education Institutions (HEI) neither communicate the urgency of soft skills development effectively to students nor do they prepare them adequately to enter the job market (Succi and Canovi, 2020). To address this, the process of change at the Durban University of Technology (DUT) is influenced by a complex interplay of drivers that encompass exciting innovations that are unique to the DUT, in particular, the Curriculum Renewal Project (CRP) with associated initiatives such as the: enrichment of the curriculum through general education (Sattar \& Cooke, 2014). As an integral part of curriculum renewal, the University decided that General Education (GE) would become a strong focus of all curricula in an endeavour to help 
students to become critical thinkers, knowledge practitioners, effective communicators and reflective learners who would function efficiently in a transformative world. Additionally, the GE modules would expose learners to diversity, globalisation, internalisation, literature and applied ethics. The brain behind the vision of GE, Professor Ahmed Bawa, indicated that employers' criticisms drove the component about learners' soft skills and at no time about their technical training skills. Developing learners as well-rounded citizens and not merely as cogs for a machine in a job market was accentuated by Bawa (Durban University of Technology, 2012). The General Education modules were interconnected to the DUT's graduate attributes. These attributes are characteristics that graduates should have attained upon graduation (DUT GE guidelines, 2012). Furthermore, the University is student-centred, which is one of the most important threads linked to general education.

"The notion of student-centeredness is that DUT exists to provide its students with the kind of learning environment that helps them grow intellectually, socially and emotionally. Student-centredness is predicated on the University's understanding of its students and what they bring with them to this place of learning so that it designs its programmes, its interactions and social interfaces, its physical spaces and its technological capacities to impact maximally on their growth as rounded, productive, responsible human beings" (DUT Strategic Plan 2015).

This significant change for the university links to the skills that employers welcome, as the notion of being educated outside one's area of expertise, is noteworthy. The University aims to address the gap between higher education and industry in anticipation of abating the joblessness that the country faces. According to Waterbury (2019), high unemployment rates can be attributed to out-dated education, inadequate funding, as well as unsuitable training. Furthermore, the impetus for educational modification is resultant from the ongoing economic crisis. Of particular concern, as stated by Liebler \& McConnel (2020), is hiring standards that need to be lowered to fill vacant positions, leading to under and non-qualified staff. The compounding effect of this is that fewer learners gain the requisite skills, knowledge and dispositions required to become meaningful contributors to society. The higher education sector has to continually modify and adapt curriculum content as graduates are expected to enter the world of work with specific relevant skills. Considering that curricular have important effects on students' professional skills (Lieu et al, 2018), through analysing students' perceptions of the undergraduate General Education modules, this research aims to ascertain learners' perspectives on the relevance of the skills acquired in the undergraduate programme.

\section{Review of Literature}

Undergraduate learners, particularly first-year learners, can be taught the skills they need to achieve their educational goals. Hence, institutions must promote first-year student success by teaching them what and the way to learn, providing them with opportunities to grow and develop, and equipping them with the necessary skills to be ready for the workforce upon graduation. This is pivotal as student development of $21^{\text {st }}$-century skills is needed to promote workforce preparedness and long-term success (Rios et al., 2020). In the work environment, industries and occupations have become redundant in a world that is characterised by automation, and artificial intelligence (AI) and the challenge rests with educators to prepare learners for the future workforce (Rampersad et al., 2019). Penprase (2018) claims that education in the future will most certainly be moulded by the industrial revolutions, with a need for higher education to address it. Thus, the acceleration of workforce re-skilling will be crucial for students to adapt to the impending changes. Education systems need to be reinvented, preparing employees to design and invent solutions to problems (Cabrita et al., 2020). Besides, changing how people communicate digitally will moreover impact on education, signifying that a response to the power of technologies is requisite. The world is in a transformative shift and is not displaying any signs of slowing down soon. Gwata (2019) articulates that education is the building block that aids in employment and is a tool for connecting people in the workplace. However, there are signs of challenges brought about by digitisation in the context of the revolutions. The workplace demand is that people are interdisciplinary, possessing skills both in their specific field as well as fields outside their specialisation. Thus, this enables one to become more economically valuable and enriched in numerous areas, presenting comprehensive skills sets to any potential labour market. However, the reality is that employees seem to regard their skills more highly than their employers that consider employees as not adequately equipped with the necessary soft skills (Tsirkas et al., 2020). Therefore, a critical requisite for education would comprise critical thinking, ethical thinking and inter-cultural awareness (Penpras, 2018) which would allow for the informed and thoughtful application of developing technologies. Furthermore, future literacy has been practised and recognised as a strategic skill that enables young people to become agents of change (Battistel et al. 2020). 
Gray (2016) highlights ten skills that are required for the future problem-solving; critical thinking; originality/creativity; people management; being able to coordinate with other people; emotional intelligence; judgement and decision making; service orientation; negotiation and reasoning flexibility. Cabrita et al. (2020) concur that education 4.0 is about thriving in a transformative world by exhibiting creativity, imaginative, innovative and critical thinking skills. Moreover, Rodny-Gumede (2019) postulate that skills and capabilities have shifted from industry-specific to transferable skills and capabilities. Further to this, Butler-Adam (2018) explains that people should have specific mandatory skills, such as literacy, numeracy and an understanding of how the world operates in the 4IR era for success as employees or members of society. HEIs are crucial players in shaping the 4IR, where people are central to the process and must be empowered. In their seminal paper, Battistel et al.. (2020) emphasise that the candidate employee in 2030 should be a proactive communicator, have digital skills including marketing and automation of production as well as other holistic and interdisciplinary skills.

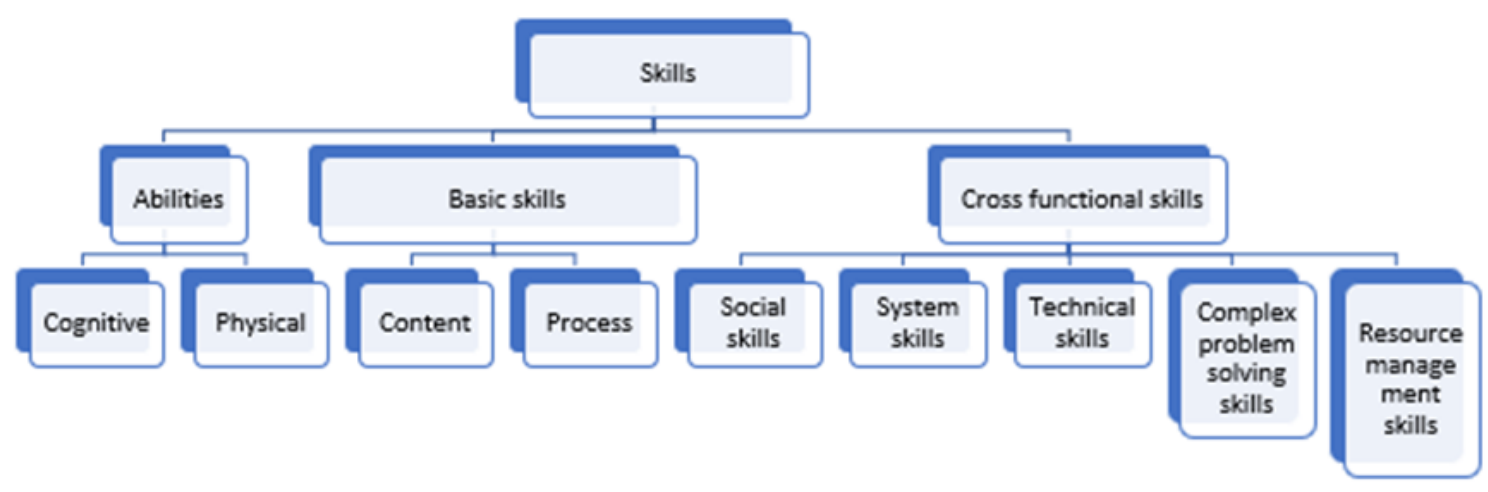

Figure 1. Core skills needed in 4IR. Source: World Economic Forum (2016)

According to Liew et al. (2018), the curriculum has a vital role to play in the learners' professional skills. Hence, it is vital for curriculum alignment to ensure that courses are designed to clearly and accurately communicate to students what they will learn and to outside stakeholders what has been learned (Shaltry, 2020). Thus, the World Economic Forum recommends that new training approaches and new education curricula must be used to develop the future workforce that is prepared for 4IR (Liew et al., 2018). Figure 1 illustrates the core skills that are required in the 4IR (World Economic Forum, 2016). Graduates must possess these skills to overcome challenges that may be encountered in the era of the 4IR. Abilities are categorised as the capacity to act mentally and physically. Secondly, basic skills are the combination of content skills, requiring active learning, ICT literacy and reading and writing. Process skills require active listening and critical thinking. Lastly, cross-functional skills are a skill set that cuts across other dimensions, including complex problem-solving and resource management skills. It, therefore, should be noted that General Education curriculum focuses on the interdisciplinary lens that helps grow one academically and professionally by reshaping one's outlook on learning; learning soft skills desired by employers and to be well-versed in a wide variety of disciplines Wallis (2020). It is important to be cognizant that a significant share of the workforce is overeducated for their job, yet under-skilled for the job's skills use requirements (Hou, 2020).

\section{Research Methodology}

The study employed the quantitative approach to gauge learner perspectives on the relevance of the skills acquired in the undergraduate programme, using a questionnaire. The researchers adopted the explanatory technique to provide an understanding of learner viewpoints on the curriculum, incorporating the modules in the undergraduate qualifications. The explanatory technique was deemed appropriate as it sets out to explain and account for the descriptive information (Boru, 2018). The instrument incorporated a five-point Likert scale, providing participants with an adequate number of opportunities to indicate a most favourable response. Moreover, an open-ended section was available, permitting participants to express their viewpoints and further supplementary comments. The target population was first-year learners from the Accounting and Informatics Faculty who were registered for the General Education modules in the undergraduate qualification. This study used the census method to collect data, which, according to Sekaran and Bougie (2016) is employed when a study attempts to collect information about the chosen population and every member in the population participates. The census was suited to this study because the population of 192 was easily accessible and manageable. The analysed sample was well represented, consisting of participants from the various race groups, 
of which $63 \%$ constituted females and $37 \%$, male. Data were analysed using Statistical Package for the Social Sciences (SPSS) and Microsoft Excel. Thematic analysis was used to conclude the analysis of the open-ended questions.

To confirm the strength of the measurement model of the study, measures of convergent validity and discriminant validity were computed (Fornell \& Larcker, 1981). In addition, variances of and co-variances amongst constructs were also calculated (Igbaria et al.,1994). The measurement model was evaluated in terms of reliability and validity, with the aid of WarpPLS 6.0 software (Kock, 2010). To test for reliability and validity, the confirmatory factor analysis (CFA) of WarpPLS was used. The reliability was measured by the estimate of internal consistency using both Cronbach's Alpha (CA) and composite reliability (CR) (Shin, 2009). All values of composite reliability and Cronbach's alpha were above 0.7, which indicates that all factors have good reliability (Henseler et al., 2009). The model's validity tells whether a measuring instrument measures what it was supposed to measure (Raykov, 2011). Validity was measured by the estimate of convergent validity and discriminate validity. Convergent validity shows the extent to which items of a specific factor represent the same factor and is measured using a standardised factor loading, which should be above 0.5 (Fornell \& Larcker, 1981).

\section{Results and Discussion}

This section presents the study's findings, with a discussion on specific modules that respondents found relevant in terms of the acquisition of skills to sustain them for the future work environment. Results on learners' perceptions on the benefits of the new modules, and their perceived outlook on the future in terms of employability, are also discussed. General education is a component included in undergraduate qualifications, consisting of modules with the aim of enhancing learners' skills. The inclusion of the GE modules was an initiative undertaken by university management based on scrupulous feedback from key stakeholders. The CRP was dubbed as one of the largest projects ever undertaken by the University. Ultimately, the buy-in on any new programme and in this case, modules, are the learners themselves and subsequently the broader workforce.

The first set of statements in the survey related to the perceived benefits of the GE modules in work preparedness. Overall, more than $20 \%$ of the participants decided to remain neutral, whilst an additional $5 \%$ did not respond, which may be due to participants being unclear on the statements. Deciding to remain neutral indicates that participants have neither a negative nor a positive response, signifying potential misperception. Another likely reason could be attributed to the cohort of learners' in the study. Level-one learners are generally unclear on what their future outlooks are, especially at the early stages of university life and hence did not feel comfortable in responding to any of the statements. Furthermore, they may have felt that they were not fully prepared to respond at that stage, and it would be interesting to re-administer the survey in their final year of study to gauge their opinions. Nonetheless, a positive $40 \%$ of participants reported that there are unquestionably current benefits from the new modules, and they are confident that these modules will contribute and add value in the future. It is refreshing to note that the University is the first to introduce a suite of modules within a well-aligned curriculum that industry so eagerly anticipates.

The second set of statements related to the various modules offered and the relevance of the curriculum and teaching, learning and assessment strategies employed in these modules. The Business Fundamentals module, being one of the GE modules introduced, was extremely well-received amongst the respondents, due to its relevance to industry and society. Presentations, group work, communication and the topic related to Accounting were identified as valueadded components to the course. Learners reported on the effectiveness of group work and presentations, emulating the business environment, as well as the support and encouragement of fellow learners. These activities helped learners develop their interpersonal skills, demonstrated how to work well in teams and how to resolve conflicts. Although many respondents did not have an Accounting background, they valued the confidence that they acquired in handling elementary Accounting tasks, mainly the topics on budgeting and the accounting equation. Accounting skills and knowledge can be applied to several industries, from the basic handling of everyday business records to more complex tasks. Coupled with useful segments, learners were enthusiastic about the reflexive journal tasks, one that permitted autonomy and unrestricted writing. Thoughtful reflections on the past allowed learners to openly express their feelings and provided them with an idea of how much they have overcome. As a result of this exercise, learners were able to shift their perspectives and mature in the process. Many learners indicated that this exercise allowed them to focus on a more positive and productive future, helping them to develop creative thinking skills and encouraging more interactivity in the work environment. Another useful exercise documented as one of the most valuable was the scenario-based exercises that were commonly administered. This allowed the business environment to be mirrored in an educational setting, hence developing and preparing learners for the world of work. Some participants indicated 
that linking student learning to real-world experiences would most likely contribute to lower apprehension levels when exposed to actual work.

On the contrary, a large percentage of participants were relatively dissatisfied with the inclusion of a Cornerstone module. The module is a compulsory institutional module for all students and hence is included in every undergraduate qualification. The module that consisted of 12 credits towards a qualification was met with reservation by many. Content incorporated was quantitative reasoning, reading, writing, language, communication and other sections. Learners expressed dissatisfaction, citing it being a complete "waste of time" and misuse of resources. A few participants mentioned the comparability of the module to school, whereby it seemed to have echoed content. Students also stated that as time passed by, they began losing interest in the module, as they felt it was unnecessary.

The third segment of questions related to learners perceptions on employability, and whether the completion of the modules would equip them with skills to be more employable in the 4IR. It was uplifting to note that well over $50 \%$ of respondents indicated that graduating with the new modules will be advantageous to them in the future. Furthermore, respondents indicated that the inherited skills, comprising both qualification-specific content and additional general diverse content, will enable them to thrive in the workplace and significantly contribute to the demands in the era of the 4IR. The 4IR is rapidly being transitioned to the fifth industrial revolution, and with continued relevant skills development, graduates will be assured of survival in this transformative world. Based on respondents' comments, the Business Fundamental module seems to have impacted on learners in anticipation of being at the forefront of employment. It appears to instil a sense of confidence in them to approach the corporate world with a sound mindset. Employability is a major crisis, not only impacting on South Africa but globally as well. More often than not, there are calls for the curriculum to foster the employability of graduates. Due to the evolving workforce in the 4IR, the curriculum will copiously prepare learners with the required knowledge and expertise that industry demands. Majority of the modules allowed for open and interactive class discussions and presentations. These methods and strategies have created a learner-centred environment whereby learners can quickly adapt to the real world and conquer complications without much effort. Skills that students have inherited from the modules will enable them to easily adapt to the ever-changing world of work as the rate of progression is at one of its fastest in terms of education and technology. Inclusive value-added modules will most certainly broaden learners' minds and change their overall future perspectives. Respondents were bold in stating their appreciation to academics who were passionate, committed to the curriculum and kept the momentum going. In some cases, learners stated that they only reported for lectures since they had adequate, continuous support and encouragement from academics. Academic support and commitment play a significant role in shaping the lives of future leaders.

\section{Conclusion}

We can safely say that we are no longer on the brink of a technological revolution but in the midst of it. HEIs are continually revising the curricula to ensure that they produce graduates who are equipped with the necessary skills required by employers. At the DUT, the expectation of the new inclusive curriculum, comprising of a suite of modules, was to ensure that learners were accomplished professionals in their preferred study areas, were broadly educated and well-rounded citizens both locally and globally. The objective of the new General Education modules was to help create learners who are critical thinkers, develop values, understand traditions, respect other cultures and opinions and make use of the acquired knowledge. The study has made a notable contribution to the body of knowledge on how learners can be represented as well-rounded, holistic graduates with specific skills that are indispensable in industry. Rampersad et al., (2019) suggested that the innovative skills required to prepare learners with the skills needed to survive in a world of automation and $\mathrm{AI}$ is lacking in undergraduate programs. In the era of the industrial revolutions, greater emphasis and importance must be placed on human intelligence, with graduates possessing skills to sustain them in an ever-changing world. It was established that the four most in-demand $21^{\text {st }}$-century skills were oral and written communication, collaboration and problem-solving (Rios et al., 2020). Both machines and humans will integrate even more during the 5IR, embodying a revolution towards a sustainable future.

The study revealed that learners' expressed satisfaction towards the various teaching, learning and assessment strategies, especially the real play project work in the Business Fundamentals modules. More importantly, the findings indicate that learners perceive that they have been equipped with the skills necessary to survive in the workplace. Pashen (2020) highlights the necessity of human actors and resources in the value co-creation process, as well as the importance of industry-specific and experience-based knowledge, further concurring that the role of humans will likely remain essential for some time. South Africa, although in its infancy with 4IR, attempts to harness the educational benefits of 4IR as it is changing every aspect of people's lives and to transform the world into a connected, augmented marketplace of ideas (DuPreez \& Sinha, 2020). "We want to be a country where our people are digital citizens, our 
workforce is skilled and empowered, and our youth enjoy the transformative benefits of employment in a new world of work", a profound statement by South Africa's president (Ramaphosa, 2020).

\section{References}

Battistel, G.A., Rb, S., Gretter, A., Ab, F., Mallossek, A., Klemenčič-Kosi, S., Birli, B., Tramberend, P., Isepponi, D., Poli, R. and Ricerca, FEMC, 2020. Skills for jobs in the 2030 Alps: participatory foresight for alpine remote areas, the pilot project ALPJOBS. Retrieved May 28, 2020, from: file://C:/Users/ferinas/Downloads/Future\%20skills\%20and\%20jobs\%20for\%20Alps\%20in\%202030.pdf

Boru, T. (2018). Chapter 5, Research Design and Methodology 5.1. Introduction: 2-41. https://doi.org/10.13140/RG.2.2.21467.62242

Butler-Adam, J. (2018). The Fourth Industrial Revolution and education. South African Journal of Science, 114(5/6), 1. https://doi.org/10.17159/sajs.2018/a0271

Cabrita, MR, Safari, H \& Dueñas, MPM. (2020). Preparing for Education 4.0: Skills Facing Economic, Social and Environmental Challenge. International Journal of Innovation, Management and Technology, 11(1), https://doi.org/10.18178/ijimt.2020.11.1.872

Du Preez, J., \& Sinha, S. (2020). Higher Education Leadership in the Era of the Fourth Industrial Revolution. The Thinker, 83(1). Retrieved August 28, 2020, from: https://journals.uj.ac.za/index.php/The_Thinker/article/view/221

Durban University of Technology. (2012). General Education Guidelines: 4

Durban University of Technology. (2015). Strategic Plan: 5

Durban University of Technology. (2020). Retrieved May 28, 2020, from www.dut.ac.za.

Fornell, C., \& Larcker, D. F. (1981). Evaluating structural equation models with unobservable variables and measurement error. Journal of marketing research, 18(1), 39-50. https://doi.org/10.1177/002224378101800104

Gray, A. (2016). World Economic Forum Report. The 10 skills you need to thrive in the Fourth Industrial Revolution. Retrieved September 24, 2019 from https://www.weforum.org/agenda/authors/alex-gray

Gwata, M. (2019). To flourish in the Fourth Industrial Revolution, we need to rethink these 3 things. Retrieved September 24, 2019 from https://www.weforum.org/agenda/2019/08/fourth-industrial-revolution-education/

Henseler, J., Ringle, C. M., \& Sinkovics, R. R. (2009). The use of partial least squares path modeling in international marketing. In New challenges to international marketing. Emerald Group Publishing Limited. https://doi.org/10.1108/S1474-7979(2009)0000020014

Hill, J., Walkington, H \& Derek, F. (2016). Graduate attributes: implications for higher education practice and policy, Journal of Geography in Higher Education, 40(2), 155-163, https://doi.org/10.1080/03098265.2016.1154932

Hou, D., Acevedo, K., de Laat, J., \& Larrison, J. (2020). Building the Right Skills for Human Capital. Retrieved September 24, 2020 from: https://openknowledge.worldbank.org/bitstream/handle/10986/34495/9781464816369.pdf?sequence=1

Igbaria, M., Parasuraman, S., \& Badawy, M. K. (1994). Work experiences, job involvement, and quality of work life among information systems personnel. MIS quarterly, 175-201. https://doi.org/10.2307/249764

Ilieva-Nawfal, E. (2020). Radical innovations as a drive of Industrial Revolutions. Science. Business. Society., 5(1), 25-28. Retrieved March 20, 2020 from https://stumejournals.com/journals/sbs/2020/1/25.full.pdf

Jones, A \& Pate, J. (2019). Students' Perceptions of Graduate Attributes: A Signalling Theory Analysis. Engaging student voices in higher education, 225-242. https://doi.org/10.1007/978-3-030-20824-0_14

Kennedy, K. (2019). Another Industrial Revolution: What schools need to know. World Economic Forum. Retrieved April 15, 2020 from: https://www.uj.ac.za/newandevents/Pages/Another-Industrial-Revolution-What-schoolsneed-to-know.aspx

Keywell, B (2017). The Fourth Industrial Revolution is about empowering people, not the rise of the machines. Retrieved March 20, 2020 from https://www.weforum.org/agenda/2017/06/the-fourth-industrial-revolution-isabout-people-not-just-machines/

Kock, N. (2010). Using WarpPLS in e-collaboration studies: An overview of five main analysis steps. International Journal of e-Collaboration (IJeC), 6(4), 1-11. https://doi.org/10.4018/jec.2010100101 
Liebler, J. G., \& McConnell, C. R. (2020). Management principles for health professionals. Jones \& Bartlett Learning. $\begin{array}{llll}\text { Retrieved } \quad \text { March } & 30, & \text { from }\end{array}$ https://books.google.co.za/books?hl=en\&lr=\&id=q6zODwAAQBAJ\&oi=fnd\&pg=PP1\&dq=Liebler, $+\mathrm{JG}+\% 26+$ McConnel,+CR.+(2020).++Management+Principles+for+Health+Professionals+8th+Edition:++128\&ots=HhEx _jhtcM\&sig=suP6TgPTwWLw8UsfX0u3ztpn52I\&redir_esc=y\#v=onepage\&q=doi\&f=false

Lieu, T. , Duc, N. , Gleason, N. , Hai, D. and Tam, N. (2018) Approaches in Developing Undergraduate IT Engineering Curriculum for the Fourth Industrial Revolution in Malaysia and Vietnam. Creative Education, 9, 2752-2772. https://doi.org/10.4236/ce.2018.916207

Memi, OB, 2020. Communication skills for jobs in the digital era. New Communication Approaches in the Digitalized World, p.348

Paschen, J., Paschen, U., Pala, E., \& Kietzmann, J. (2020). Artificial intelligence (AI) and value co-creation in B2B sales: Activities, actors and resources. Retrieved from http://urn.kb.se/resolve?urn=urn:nbn:se:kth:diva-268987

Penprase, B. E. (2018). The fourth industrial revolution and higher education. Higher education in the era of the fourth industrial revolution, 207. https://doi.org/10.1007/978-981-13-0194-0_9

Ramaphosa, C. (2020). A national strategy for harnessing the Fourth Industrial Revolution: The case of South Africa. Africa in focus: 1 Retrieved from https://www.brookings.edu/blog/africa-in-focus/2020/01/10/a-nationalstrategy-for-harnessing-the-fourth-industrial-revolution-the-case-of-south-africa/

Rampersad, G. C., \& Zivotic-Kukuloj, V. (2019, May). Future of Work: Innovation Skills as the Missing Link for Employability. In Proceedings of The Australian Conference on Science and Mathematics Education (formerly UniServe Science Conference) (pp. 129-135). Retrieved from https://openjournals.library.sydney.edu.au/index.php/IISME/article/view/12877/12129

Raykov, T. (2011). Evaluation of convergent and discriminant validity with multitrait-multimethod correlations. British journal of mathematical and statistical psychology, 64(1), 38-52. https://doi.org/10.1348/000711009X478616

Rios, J. A., Ling, G., Pugh, R., Becker, D., \& Bacall, A. (2020). Identifying critical 21st-century skills for workplace success: a content analysis of job advertisements. Educational Researcher, 49(2), 80-89. https://doi.org/10.3102/0013189X19890600

Rodny-Gumede ,Y. (2019). The Fourth Industrial Revolution, the changing world of work and imperatives of internationalisation in higher education. The Thinker, A Pan African Quarterly thought for leaders, 82, 57-60

Sattar, K. \& Cooke, L.A. (2014). A position paper: Conceptualising the quality assurance of graduate attributes at the Durban University of Technology. Centre for Quality Promotion and Assurance. Durban University of Technology (Unpublished).

Scepanovič, S. (2019). The Fourth Industrial Revolution and Education. 8th Mediterranean Conference on Embedded Computing (MECO), Budva, Montenegro, 1-4, https://doi.org/10.1109/MECO.2019.8760114

Sekaran, U \& Bougie, R. (2016). Research Methods for Business: A Skill-Building Approach. $7^{\text {th }}$ Ed. Chichester, West Sussex: Wiley.

Shaltry, C. (2020). A new model for organizing curriculum alignment initiatives. Adv Physiol Educ, 44, 658 - 663, 2020; https://doi.org/10.1152/advan.00174.2019

Shin, D. H. (2009). An empirical investigation of a modified technology acceptance model of IPTV. Behaviour \& Information Technology, 28(4), 361-372. https://doi.org/10.1080/01449290701814232

Succi, C., \& Canovi, M. (2020). Soft skills to enhance graduate employability: comparing students and employers' perceptions. Studies in Higher Education, 45(9), 1834-1847. https://doi.org/10.1080/03075079.2019.1585420

Teo, P. (2019). Teaching for the 21st century: A case for dialogic pedagogy. Learning, Culture and Social Interaction, 21, 170-178. https://doi.org/10.1016/j.lcsi.2019.03.009

Tsirkas, K., Chytiri, A.-P. and Bouranta, N. (2020). The gap in soft skills perceptions: a dyadic analysis. Education + Training, 62(4), 357-377. https://doi.org/10.1108/ET-03-2019-0060

Wallis, A. (2020). Why are General Education courses important? Retrieved October 24, from https://www.snhu.edu/about-us/newsroom/2018/08/why-are-general-education-courses-important 
Waterbury, J. (2019). Reform of Higher education in the Arab world. Major Challenges facing higher education in the Arab world: Quality Assurance and relevance, 133. https://doi.org/10.1007/978-3-030-03774-1

Wessels, L. (2020). How South African universities can contribute to preparing the future workforce for the Fourth Industrial Revolution (Doctoral dissertation).

World Economic Forum. (2016, January). The future of jobs: Employment, skills and workforce strategy for the fourth industrial revolution. In Global challenge insight report. Geneva: World Economic Forum. Retrieved March 20, 2020 from http://www3.weforum.org/docs/WEF_Future_of_Jobs.pdf

\section{Copyrights}

Copyright for this article is retained by the author(s), with first publication rights granted to the journal.

This is an open-access article distributed under the terms and conditions of the Creative Commons Attribution license (http://creativecommons.org/licenses/by/4.0/). 